\title{
COMPARTIR ALIMENTOS EN EL MICHOACÁN DEL SIGLO XV
}

\author{
Sharing Food in Michoacan during the $15^{\text {th }}$ Century \\ Rodolfo FERnÁNDEZ y Daria DeRAgA ${ }^{1}$ \\ Instituto Nacional de Antropología e Historia, México
}

\section{Resumen}

La práctica de compartir alimentos en el Michoacán del siglo XV mesoamericano es descrita con amplitud en el documento llamado La Relación de Michoacán, una famosa obra literaria del siglo XVI escrita por un fraile franciscano a partir de testimonios de informantes indios, hacia 1540 . En ella se describe con riqueza y profusión de detalles cómo los tarascos ofrecían alimentos a sus huéspedes o a sus pares de otros señoríos en todo tipo de reuniones y, con gran énfasis, en los contextos ceremoniales. Es nuestro propósito dar a conocer y analizar algunas de las prácticas recogidas en nuestra fuente documental, referidas expresamente a comidas rituales en las que la comida se comparte.

Palabras clave: Michoacán, tarasco, comida ritual, alimento compartido, Nueva España

\section{Abstract}

The practice of sharing food in Michoacán in the Mesoamerican $15^{\text {th }}$ Century is amply described in the document called La Relación de Michoacán, a famous literary work of the $16^{\text {th }}$ Century written by a Franciscan monk, based on Indian informants around 1540. In the document there are richly and profusely described details of how the Tarascans offered food to their visitors or equals from other communities in all types of reunions, and with great emphasis on ceremonial context. It is our intention to show and analyze some of the practices recovered from our documental source, with reference expressively to ritual food which is shared.

Key words: Michoacán, tarasco, ritual food, shared food, New Spain

1 Rodolfo Fernández es doctor en Ciencias Sociales y en Letras e investigador vinculado al Centro INAH de Jalisco. Correo electrónico: rffernandez44@gmail.com. Daría Deraga es doctora en Ciencias Sociales e investigadora del INAH-Jalisco. Correo electrónico: dderaga@ gmail.com. Fecha de recepción del artículo: 2 de julio de 2016. Fecha de aceptación del artículo: 5 de septiembre de 2016 . 


\section{INTRODUCCIÓN}

En la Relación de Michoacán, ${ }^{2}$ documento del siglo XvI escrito por un fraile franciscano, pronto se hace notar que las comidas rituales tenían lugar prácticamente en todas las reuniones importantes, a menudo acompañadas de bebidas alcohólicas y suelen registrarse en contextos de fuerte contenido simbólico, a veces trascendental, en el devenir épico de los michoacanos. En las siguientes páginas ofrecemos una serie de ejemplos seleccionados que permiten percatarnos de la importancia que el acto de compartir alimentos tenía entre los tarascos. También observaremos cómo esta práctica queda registrada en una amplia gama de eventos como bodas, tomas de posesión por gobernantes locales o reuniones de señores para discutir asuntos de trascendencia. ${ }^{3}$

\section{LA RELACIÓN DE MICHOACÁN Y EL CONSUMO COMPARTIDO DE ALIMENTOS}

En el primer caso que documentamos en la Relación, el consumo compartido de alimentos simboliza y explica el rencuentro entre dos grupos étnicos emparentados entre sí pero que habían permanecido aislados durante unos seis siglos.

Al reencontrarse, el grupo que había permanecido en la cuenca lacustre de Pátzcuaro, seguía siendo un pueblo de pescadores y agricultores. El otro grupo, integrado por quienes habían migrado hacia el Norte, se había convertido en un pueblo de cazadores-recolectores; pero en las tierras donde se asentaron y desarrollaron esta nueva realidad socioeconómica,

2 Jerónimo de Alcalá, Relación de las ceremonias y rictos y población y gobernación de los indios de la provincia de Michoacán (coord. Moisés Franco Mendoza), Zamora, Mich., El Colegio de Michoacán-Gobierno del estado de Michoacán, 2000. La Relación de Michoacán es un texto novohispano, de autor no explícito; data, de manera aproximada, del segundo cuarto del siglo XVI, y su destinatario principal parece haber sido el virrey Antonio de Mendoza. Se puede considerar como una obra pionera del conjunto de textos posteriores que Walter Mignolo designa como 'relaciones de la conquista y de la colonización.' De acuerdo con Mignolo, estas relaciones se caracterizan por sus rasgos pragmáticos y organizativos; y se distinguen del grupo de las 'cartas relatorias' y del de las 'crónicas' o 'historias'. El núcleo de este tipo discursivo lo ejemplifican las Relaciones geográficas de Indias. Walter Mignolo, «Cartas, crónicas y relaciones del descubrimiento y la conquista», en Luis Íñigo Madrigal, coord., Historia de la literatura hispanoamericana, tomo I: Época Colonial, Madrid, Cátedra, 1992, pp. 57-116.

3 Una primera versión de este trabajo fue presentada al $31 .{ }^{\circ}$ Congreso Internacional de ICAF, Partager la nourriture celebrado en Lasseube (Francia). 
los cambios climáticos y las fluctuaciones de la frontera agrícola constituyeron fenómenos que los impulsaron a migrar de nuevo al sur, al territorio de donde habían partido. En la Relación de Michoacán el reencuentro simbólico tiene lugar cuando dos señores del principal grupo cazador, el de los uacúsecha, se acercan a la orilla del lago, en cuya proximidad pescaban otro par de señores de uno de los grupos sedentarios, pero pescadores, que habían permanecido en la cuenca de Pátzcuaro.

$\mathrm{Al}$ acercarse los recién llegados a la margen del lago, vieron a uno de aquellos pescadores en una canoa, pescando con anzuelo. Lo llamaron y le preguntaron que hacía. El pescador respondió en la lengua de los recién llegados pero con cierto recelo pues los intrusos utilizaban muchas expresiones corruptas y serranas. Según explica el texto, ello se debía a que eran chichimecas, mote con que se denominaba a las tribus cazadoras norteñas, y entre las cuales, con el paso del tiempo, se habían integrado los recién regresados al lago (Hers, 2009).

El pescador interpelado fue llamado a la orilla pero, en un principio se negó a responder, por miedo a ser flechado. Después aceptó y uno de los chichimecas, llamado Vápeani, saltó a la canoa y le preguntó qué era aquello que tenía en el fondo de la barca. El isleño contestó que era pescado y le mostró tres variedades. Luego agregó que de noche pescaba con red y de día con anzuelo. El uacúsecha inquirió acerca del sabor de aquello y el isleño respondió, que si tuvieran fuego se lo daría a probar. El chichimeca le pidió cortar leña, le aclaró que ellos de continuo encendían fuego y sacó para ello el avío instrumental pertinente. A continuación hizo una lumbrada en la que el isleño empezó a asar aquellos pescados y conforme se cocinaban, aquellos hombres los iban comiendo. A los chichimecas les agradó su sabor. (Págs.: 352, 1.27-353, 1.33).

Como los recién llegados comían todo lo cazable, traían consigo redes llenas de conejos, cuinques, codornices, palomas y otras aves. Sacaron, en primer lugar, un conejo y lo asaron con piel y todo, para posteriormente desollarlo y comerlo compartiendo con el pescador a quien le explicaron que ese tipo de animales era lo que ellos solían buscar para comer. El pescador respondió que eso sí era comida, en comparación con la casi exclusiva ingesta de pan de su dieta. Y añadió que, además, no era un alimento hediondo como el pescado. Seguidamente explicaron al aldeano que acostumbraban a hacer un día flechas para, al siguiente día, ir al campo a recrearse cazando venados. Venados que no cazaban para sí, sino para alimentar al sol, a los dioses celestes engendradores y a las cuatro partes del mundo. La carne de estos animales sólo era consumida por 
los uacúsechas después de «haber hecho la salva a los dioses». (Págs.: 353, 1.33-354, 1. 16).

Así, en este primer caso, el amigable reencuentro entre individuos que no se conocen pero se expresan en una lengua similar, se sustenta en relación entablada a través del acto de compartir lo que cada cual ha cazado y ha pescado y que se pone en común para ser cocinado y consumido mientras pescador y cazadores conversan acerca de los rituales uacúsechas de ofrecer y compartir determinados productos de caza con las fuerzas divinas y naturales.

$*$

Más adelante, en el capítulo XI de la Relación, queda consignado otro ejemplo sobre consumo compartido de alimentos entre estos pueblos. Carícaten, el señor de los isleños, ordena a sus mensajeros ir con Zurumban, el señor de Taríaran - otro de los señoríos sedentarios de la cuenca lacustre-, para pedirle ayuda contra Taríacuri, el señor de los recién llegados chichimecas. El mensaje al señor de Taríaran es claro: Carícaten le manda decir que si se lo proponían, juntos podrían destruir en una mañana a los chichimecas.

Con este mismo propósito, Zurumban envía a su sacerdote Naca a que alerte a otro grupo sedentario más, el de Curínguaro, el señorío dominante de la cuenca, informándoles del plan. Les manda decir que se reúnan en Xarácuaro con los isleños, donde ellos acudirán también, para posteriormente ir al encuentro de los chichimecas para matarlos. En el camino de regreso, Naca, el enviado, pasa por un sitio llamado Zyráueni, donde come con el señor que domina esa tierra, Quarácuri, y aparentemente lo convence de participar en la incursión contra los uacúsecha, sin percatarse de que Quarácuri es aliado de los uacúsechas.

La narración de este episodio continúa en el siguiente capítulo, el XII: una vez que el sacerdote Naca se marcha, el señor Quarácuri envía un mensaje a su aliado Taríacuri, el señor chichimeca, avisándole de que Naca pasó por su pueblo reuniendo gente de guerra. Taríacuri piensa una estratagema y pide al enviado que trate de localizar a Naca, se haga el encontradizo y, con la intención de sonsacarle la ruta de regreso que seguirá tras cumplir con su cometido, le comunique que Quarácuri se siente avergonzado de haberle ofrecido poca comida cuando pasó por su casa y que, en desagravio, lo quiere agasajar con mejores manjares cuando regrese de re- 
clutar gentes para la guerra contra los uacúsechas. Es en este momento de la narración, cuando se inserta el breve pasaje en el que Quarácuri hace llegar un mensaje a Naca para sonsacarle su ruta de regreso y se especifica el refrigerio que compartirá con el sacerdote:

Señor, tu hermano Quarácuri me envía a ti y díjome: 'Ve a mi hermano Nacá y dile que rescebí mucha vergüenza en dalle tan poco a comer. Pregúntale en qué día y de aquí a qué tanto volverá, porque le espere con comida a la vuelta. Y haré pan de bledos y vino de maguey para que beba a la vuelta, porque hace calor y tienen sed los caminantes'. Esto le dirás por saber el día en que ha de venir y segund lo que te dijere, así le irás respondiendo. Y dirasle más: 'Dice también tu hermano que por qué camino has de venir, porque hay dos caminos.' (Cap. XII)

De este modo, con la respuesta obtenida, Quarácuri averigua cuál es el camino que Naca tomará y avisa a Taríacuri. El chichimeca envía a sus hermanos Zétaco y Aramen tras el sacerdote, que es alcanzado, herido y capturado. Una vez en su poder, Taríacuri manda llevarlo al adoratorio para sacrificarlo.

La narración prosigue en los capítulos XIII y XIV con otro nuevo acto de compartir alimento. Una vez inmolado el sacerdote, Taríacuri llama a sus criados para que despedacen el cuerpo de Naca y envíe los trozos cortados a los tres señoríos aliados en su contra, con la intención de que sus rivales los consuman pensando que es un obsequio comestible de carne de esclavo. Seguidamente, a través del mismo Quarácuri, Taríacuri envía a un mensajero, buen corredor, con la misión de que, tan pronto como sean consumidos en los señoríos los trozos despedazados de Naca, haga saber a los enemigos que han ingerido a su propio sacerdote y no a un esclavo, como les habían hecho creer. En cuanto da la noticia, el corredor huye a toda velocidad (Cap. XIII). Al ser conocedor Zurumban de que han ingerido la carne del sacerdote y que el engaño fue idea de Taríacuri, en venganza manda destruir las casas de sus hermanos, Zétaco y Aramen. También ordena vejarlos y deshonrar a sus mujeres. (Cap. XIV).

$*$

Otro episodio de la Relación de Michoacán en que el acto de compartir alimentos es trascendental tiene lugar en el capítulo XV. La narración cuenta cómo Taríacuri se casó con la hija del señor de Curínguaro, el señorío sedentario dominante, y cómo ésta fue mala mujer. 
Al inicio del relato, el señor de Curínguaro manda ofrecer en matrimonio a una de sus hijas a Taríacuri, señor de los chichimecas, con la idea subyacente de que ella tenga un hijo de Taríacuri y con ello se logre acceder al favor de Curícaueri, su dios principal. Taríacuri acepta. En pocos días la esposa se queda preñada. Pero ella, sin permiso, sigue acudiendo a Curínguaro, su pueblo, donde se emborracha en las casas de los ancianos y de sus amigos y con el tiempo ya no regresa con su marido. Taríacuri decide ir a buscarla, para lo cual reúne a su gente, toma leña y un venado y parte hacia Curínguaro con la intención de presentar y ofrendar el dicho animal al dios del pueblo de su esposa. A su llegada, el suegro le dice:

'Seáis bien venido, padre de Curátame', que se llamaba así su nieto, el hijo de Taríacuri. Y saludole así mismo Taríacuri a su suegro. Y díjole su suegro: 'Muy bien, me contenta como vienes y la caza que trais. Cierto que eres mi hijo. Desuéllale tú, que no sabemos nosotros y con él quitaremos la embriaguez.' Y descuartizole Taríacuri y él mesmo asaba del venado para su suegro que andaba sudando, y dioles a todos unos torreznos o pedazos del venado asado. Y díjole su suegro: 'Pues hijo, ¿por qué no trujiste tu mujer contigo? ¿Por qué eres tan celoso? Y comiéramos aquí todos y estuviéramos aquí en conversación un poco?' Díjole Taríacuri: 'No la truje, que no venía a entrar en tu casa, mas vine a dar ofrenda de leña a Uréndequavécara. Y por esto sólo vine a entrar en tu casa, por el venado que tomamos cabe Zirýnbaro. Allí le sacrifiqué y por esto vine acá.' Dijo el suegro: 'Bebe, que yo te quiero dar a beber.' Dijo Taríacuri: 'No tengo de beber que me tomo luego del vino y caireme aquí, encima de vosotros, porque me tomo muy malamente.' (Págs. 405, 1. 23-406, 1. 9).

El pasaje señala que el joven señor cazador llega a casa de su suegro con el pretexto de llevar una ofrenda a su dios, y llegado el momento de destazar el venado y cocinarlo, el suegro le pide que lo haga él, haciendo alusión implícita a su aptitud para ello por su condición cazadora. Y habiéndolo asado, procede Taríacuri a repartir entre los presentes trozos de aquella presa para que los consuman. A continuación, el suegro le ofrece de beber, pero Taríacuri se niega aludiendo a la facilidad con que se embriaga. Lo que queremos poner de relieve con este ejemplo es que el acto de compartir comida y bebida alcohólica se conforma como una acción de comensalidad con unos alimentos concretos que, en la evolución de narración, se tornan necesarios para dar sentido al reclamo del yerno al suegro por la conducta de su hija.

El capítulo XVI contiene otro ejemplo interesante de consumo compartido de alimentos y en este caso se pone énfasis en la bebida. El pasaje relata cómo vinieron los amigos de la esposa infiel de Taríacuri «y cómo se em- 
borracharon con ella y de la falsedad que levantaron a Tariacuri». La historia narrada comienza cuando Taríacuri, pasados algunos días del episodio anterior, se preparaba para el 'sacrificio de las orejas' que en esa época del año se practicaba en el contexto de una fiesta. Entonces aparecieron dos hombres y Taríacuri los mandó recibir. Su mujer, la curinguareña, también los recibió entusiasmada de su presencia. Fueron agasajados con comida y bebida. Taríacuri se excusó de beber con ellos y se fue al monte por unas matas de trébol para el resfriado. Una vez que se hubo marchado, su mujer se emperifolló y asumió el papel de anfitriona. Entonces, «enfrente de ellos les escanciaba y ellos empezaron a retozarla...» A su llegada, Taríacuri la sorprendió borracha y tiznada por el contacto físico con sus amantes, pero ella fingió estar enferma. Taríacuri no la tocó y regresó al monte. Posteriormente, los adúlteros se sacrificaron las orejas y culparon a Taríacuri de haberles mutilado.

El episodio continúa e insiste en señalar la infidelidad de aquella mujer. Una infidelidad que, de nuevo, es asociada al consumo compartido de alimentos y bebida y que el texto de La Relación de Michoacán utiliza para reforzar el contraste con la rectitud ostensible del esposo. Es una secuencia de censuras a la esposa y los adúlteros y de elogios al esposo anfitrión. La narración quiere poner de relieve, además, el hecho de que la libidinosa mujer es quien escancia el vino a sus anfitriones una vez que su marido, evitando de nuevo beber, va al monte en busca de hierbas medicinales. $\mathrm{He}$ aquí el fragmento de texto que lo relata:

Y como se hubo salido de casa Taríacuri, ataviase muy bien su mujer, después dél ido, y dijo aquellos mancebos: 'Váyase Taríacuri, no recebáis pena, que en esta casa no mora Taríacuri, sino yo, questa es su costumbre de ir por leña y no se emborracha. Yo os escanciaré'. Y empenzó a escanciar y era un poco noche cuando se llegó cerca dellos [...] y estuvo con ellos aquella noche diciéndole: 'hermana acá y hermana acullá'. Y como estaban ellos entiznados, entiznáronla toda la cara y los vestidos. Y a la mañana fuéronse a su pueblo y entrose la mujer en su casa. (Págs.: 410, 1. 22-411, 1.3).

Para terminar, nos queremos referir a varias alusiones al consumo compartido de alimentos que registra la Relación de Michoacán en su tercera parte. En ella, se consignan eventos repetibles que relatan costumbres rituales y que el autor de la obra recogió de sus informantes. Por ejemplo, el capítulo quinto de esta tercera parte trata de «Cómo destruían o combatían los pueblos» señalando que, al tiempo de reunirse para la acción guerrera, 
[...] cada pueblo se llevaba sus vituallas y así se partía toda aquella gente de los pueblos y por los pueblos que pasaban les sacaban al camino mucha comida, y antes que llegasen donde habían de sentar el real, juntábanse todos y entiznábanse toda la gente y los sacerdotes que llevaban a los dioses. (f. 16, 11. 20-25).

Vemos que el compilador de los relatos resalta la costumbre de sacar alimentos al camino cuando se producía el paso de los contingentes rumbo a la conquista de otros pueblos. Pero además expresa otra práctica, más generalizada: la de llevar al sendero un refrigerio a los allegados que transitaban por él. Y nos recuerda el caso de Naca, el sacerdote a quien Quarácuari ofreció lo que hoy podríamos llamar 'horchata y alegrías' a su paso por el pueblo de Quarácuari.

Más adelante, en el capítulo noveno de esta tercera parte, donde trata «De la muerte de los caciques y como se ponían otros», el cazonci, señor principal, hacía a los nuevos caciques la siguiente recomendación: «Entra en las casas de los papas a tu oración y retén los vasallos de nuestro dios Curícaveri, que no se vayan a otra parte, y no comas tú solo tus comidas; mas llama la gente común y dales de lo que tuvieres; con esto guardarás la gente y los regirás» (f. 22). En este caso, estamos ante un compartir y comer juntos que estrecha lazos de fidelidad y relaciones jerárquicas, de preeminencia y de sumisión.

Señalaremos un último ejemplo, en el capítulo undécimo, también en esta tercera parte, titulado «Los señores entre sí, se casaban de esta manera». En este pasaje encontramos una brevísima y muy bella alusión al consumo compartido de alimentos. En cierto momento de la ceremonia, el sacerdote les daba consejos a los jóvenes contrayentes y, «acabados sus razonamientos, comían todos en uno; y daban de aquellos tamales grandes [...] y otras comidas. Y mostrábales el suegro las sementeras que les daba para sembrar, y dábanles mantas al sacerdote y a las mujeres que la habían llevado». La referida comida, por cierto, llamada en el texto "pan de boda» consistía en «unos tamales muy grandes llenos de frijoles molidos» y constituye un ritual alimentario constatado en culturas de muy diversos espacios y tiempos.

\section{Conclusión}

Los ejemplos seleccionados y expuestos permiten percatarnos e incidir en la importancia que el acto de compartir alimentos tenía entre los tarascos. En otros trabajos realizados se ha puesto énfasis en la tópica retórica del culto a los dioses como elemento organizador del discurso central en la 
Relación de Michoacán (Fernández, 2010 y 2011). En esta ocasión, hemos querido incidir y demostrar que el consumo compartido de alimentos y bebida se halla asociado a episodios trascendentes de la obra, episodios que en no pocas ocasiones están cargados de un gran valor simbólico, como el encuentro entre los grupos sedentarios y los cazadores chichimecas recién llegados, los pasajes asociados al matrimonio de Taríacuri y el repudio de su mujer por infiel y libidinosa, las ocasiones en que se legitimaba un nuevo señor o con motivo del matrimonio entre señores.

Por otra parte, hay que prestar atención al tipo de alimentos que se parten o distribuyen para su consumo conjunto. Los alimentos que se comparten son coherentes con el grado de organización social que poseen quienes distribuyen aquella comida. Cuando el texto se refiere, por ejemplo, a los uacúsecha - cuya organización interna gira en torno a la cazaTaríacuri lleva a casa de su suegro un venado que cazó en camino; y cuando se encuentran chichimecas e isleños, los primeros ofrecen presas cinegéticas mientras que los segundos comparten el producto de su actividad económica principal, el pescado.

Cuando se comparte carne humana, aunque haya sido con intención de engaño, el pasaje retrata algo que parece haber sucedido con cierta frecuencia y que en modo alguno se incluye en la narración como un recurso literario para afear actitudes fuera de la norma. En este sentido, es muy significativo el episodio que narra José Francisco Román, ocurrido en Tequila, hoy Jalisco, en 1550, según el relato del oidor Martínez de la Marcha:

En este sitio realizó informaciones acerca de los indios llamados Tezoles, acusados de haber dado muerte al alcalde de Tequila y realizado prácticas idolátricas en sus antiguos templos; allí mismo mostraron al oidor 'un cuarto del dicho alcalde que los indios tezoles habían enviado en señal de amistad a sus vecinos, los de Guajacatlán.'4

La práctica de compartir alimentos queda registrada en una amplia gama de pasajes diferentes, como bodas, tomas de posesión por gobernantes locales, reuniones de señores para discutir asuntos de trascendencia, encuentros informales a la vera de un camino al paso de un viajero... También se registra en actos de asistencia y apoyo a contingentes que se dirigían a acciones bélicas. Sin olvidar el especial significado de ese consumo

4 José Francisco Román Gutiérrez, Sociedad y evangelización en Nueva Galicia durante el siglo XVI, Guadalajara, El Colegio de Jalisco-Universidad Autónoma de Zacatecas-Instituto Nacional de Antropología e Historia, 1993, pp. 69 y 131. 
compartido de alimentos en el pasaje mítico de encuentro entre cazadores recolectores y sedentarios, un pasaje que al ser relatado por el autor de la Relación de Michoacán imprime a esta obra una carga retórica trascendental en lo tocante al derecho de dominio que los uacúsecha alegan tener sobre los demás pueblos tarascos, por cuestión de parentesco.

\section{REFERENCIAS BIBLIOGRÁFICAS}

AlCALÁ, Jerónimo de, 2000, Relación de las ceremonias y rictos y población y gobernación de los indios de la provincia de Michoacán (coord. Moisés Franco Mendoza), Zamora, Mich., El Colegio de Michoacán-Gobierno del estado de Michoacán.

FernANDEZ, Rodolfo, 2011, Retórica y antropología del mundo Tarasco: testo sobre la ¿Relación de Michoacán'. México, INAH.

FERNÁNDEZ, Rodolfo, 2010, «Comida ritual y hábitos alimenticios en el Michoacán de los siglos XV y XVI». Historias, 76 (mayo-agosto 2010): 27-37.

Hers STUTZ, Marie-Areti, 2009, «Los chichimecas: ¿nómadas o sedentarios?» En Andrés Fábregas Puig, Mario-Alberto Nájera Espinoza y Claudio Esteva Fabregat, coords., Continuidad y fragmentación de la Gran Chichimeca. Guadalajara (Jalisco), Universidad de Guadalajara: 33-59.

Mignolo, Walter, 1992, «Cartas, crónicas y relaciones del descubrimiento y la conquista». En Luis Íñigo Madrigal, coord., Historia de la literatura hispanoamericana. Tomo I: Época Colonial. Madrid, Cátedra: 57-116.

RomÁn GuTtírREZ, José Francisco, 1993, Sociedad y evangelización en Nueva Galicia durante el siglo XVI. Guadalajara, El Colegio de Jalisco-Universidad Autónoma de Zacatecas-Instituto Nacional de Antropología e Historia. 